\title{
The glycinergic system in human startle disease: a genetic screening approach
}

\section{Jeff S. Davies ${ }^{\text {* }}$, Seo-Kyung Chung ${ }^{1}$, Rhys H. Thomas', Angela Robinson', Carrie L. Hammond ${ }^{1}$, Jonathan G. L. Mullins' ${ }^{1}$, Eloisa Carta ${ }^{2}$, Brian R. Pearce ${ }^{2}$, Kirsten Harvey ${ }^{2}$, Robert J. Harvey ${ }^{2}$ and Mark I. Rees ${ }^{1,3}$}

1 Institute of Life Science, School of Medicine, Swansea University, Singleton Park, Swansea, UK

2 Department of Pharmacology, The School of Pharmacy, London, UK

3 Institute of Medical Genetics, School of Medicine, Cardiff University, Cardiff, UK

\section{Edited by:}

Jean-Michel Rigo, Universiteit Hasselt, Belgium

\section{Reviewed by:}

Hans-Georg Breitinger, The German University in Cairo, Egypt

C. Gimenez, Universidad Autonoma de Madrid, Spain

\section{${ }^{*}$ Correspondence}

Jeff S. Davies, Institute of Life Science, School of Medicine, Swansea

University, Singleton Park SA2 8PP, UK. e-mail: jeff.s.davies@swansea.ac.uk
Human startle disease, also known as hyperekplexia (OMIM 149400), is a paroxysmal neurological disorder caused by defects in glycinergic neurotransmission. Hyperekplexia is characterised by an exaggerated startle reflex in response to tactile or acoustic stimuli which first presents as neonatal hypertonia, followed in some with episodes of life-threatening infantile apnoea. Genetic screening studies have demonstrated that hyperekplexia is genetically heterogeneous with several missense and nonsense mutations in the postsynaptic glycine receptor (GlyR) $\alpha 1$ subunit gene (GLRA1) as the primary cause. More recently, missense, nonsense and frameshift mutations have also been identified in the glycine transporter GlyT2 gene, SLC6A5, demonstrating a presynaptic component to this disease. Further mutations, albeit rare, have been identified in the genes encoding the GlyR $\beta$ subunit (GLRB), collybistin (ARHGEF9) and gephyrin (GPHM - all of which are postsynaptic proteins involved in orchestrating glycinergic neurotransmission. In this review, we describe the clinical ascertainment aspects, phenotypic considerations and the downstream molecular genetic tools utilised to analyse both presynaptic and postsynaptic components of this heterogeneous human neurological disorder. Moreover, we will describe how the ancient startle response is the preserve of glycinergic neurotransmission and how animal models and human hyperekplexia patients have provided synergistic evidence that implicates this inhibitory system in the control of startle reflexes.

Keywords: glycine, hyperekplexia, receptor, transporter, mutation

\section{INTRODUCTION TO HYPEREKPLEXIA}

Glycine receptors (GlyR) are heteropentameric ligand-gated chloride ion channels that facilitate fast inhibitory neurotransmission in the human central nervous system (CNS) (Lynch, 2009). In humans, GlyRs have four functional subunits, GlyR $\alpha 1-\alpha 3$ and $\beta$ that exist in heteromeric $\alpha \beta$ combinations although the exact stoichiometry is a matter of intense debate (Grudzinska et al., 2005). Dysfunction of inhibitory glycinergic neurotransmission causes startle disease/hyperekplexia in humans (OMIM 149400), characterised by neonatal hypertonia and an exaggerated startle reflex in response to tactile or acoustic stimuli. In some instances, this can result in life-threatening infantile apnoea episodes. The most common disease-causing genes are those encoding the postsynaptic GlyR $\alpha 1$ subunit (GLRA1) on chromosome 5q33.1 (Shiang et al., 1993, 1995; Rees et al., 1994, 2001) and the presynaptic glycine transporter GlyT2 (SLC6A5) on chromosome 11p15.2 (Eulenburg et al., 2006; Rees et al., 2006). Both disease loci have revealed dozens of pathogenic missense, nonsense and frameshift mutations that can be inherited in either a dominant or recessive manner, with several recurrent mutations in GLRA1 (Figure 1).

The description of mutations in the GlyR $\alpha 1$ subunit gene by Shiang et al. (1993) was the first channelopathy associated with ligand-gated chloride channels, whilst the mutations in the GlyT2 gene reported by Rees et al. (2006) defined the first neurological disorder linked to a defect in presynaptic transporter for a classical fast-acting neurotransmitter. However, both studies owe a great debt to murine models of hyperekplexia which revealed key candidate genes for the human screening programme (Becker et al., 1992; Buckwalter et al., 1994; Kingsmore et al., 1994; Mülhardt et al., 1994; Ryan et al., 1994; Gomeza et al., 2003a). Screening of genes encoding additional postsynaptic proteins involved in GlyRmediated transmission including the GlyR $\beta$ subunit (GLRB; Rees et al., 2002), gephyrin (GPHN; Rees et al., 2003) and collybistin (ARHGEF9; Harvey et al., 2004) has revealed only single individuals with potential mutations in these genes. Although mutations in GLRB are a clear cause of exaggerated startle in humans and animals (Kingsmore et al., 1994; Mülhardt et al., 1994; Rees et al., 2002; Hirata et al., 2005), deletions in GPHN have been associated with molybdenum co-factor deficiency (Reiss et al., 2001), whilst gene rearrangements in ARHGEF9, encoding the RhoGEF collybistin are more commonly associated with X-linked mental retardation(Harvey et al., 2008b; Marco et al., 2008; Kalscheuer et al., 2009). Despite our successes in disease gene discovery, approximately $35 \%$ of the hyperekplexia patients we recruited to our cohort studies are devoid of mutations in genes encoding postsynaptic GlyRs, associated proteins and the presynaptic transporter GlyT2. Although our knowledge of the proteomics of glycinergic synapses is extremely limited, this suggests that other genes encoding presynaptic transporters or receptor/transporter-associated proteins are suitable candidates for mutation 


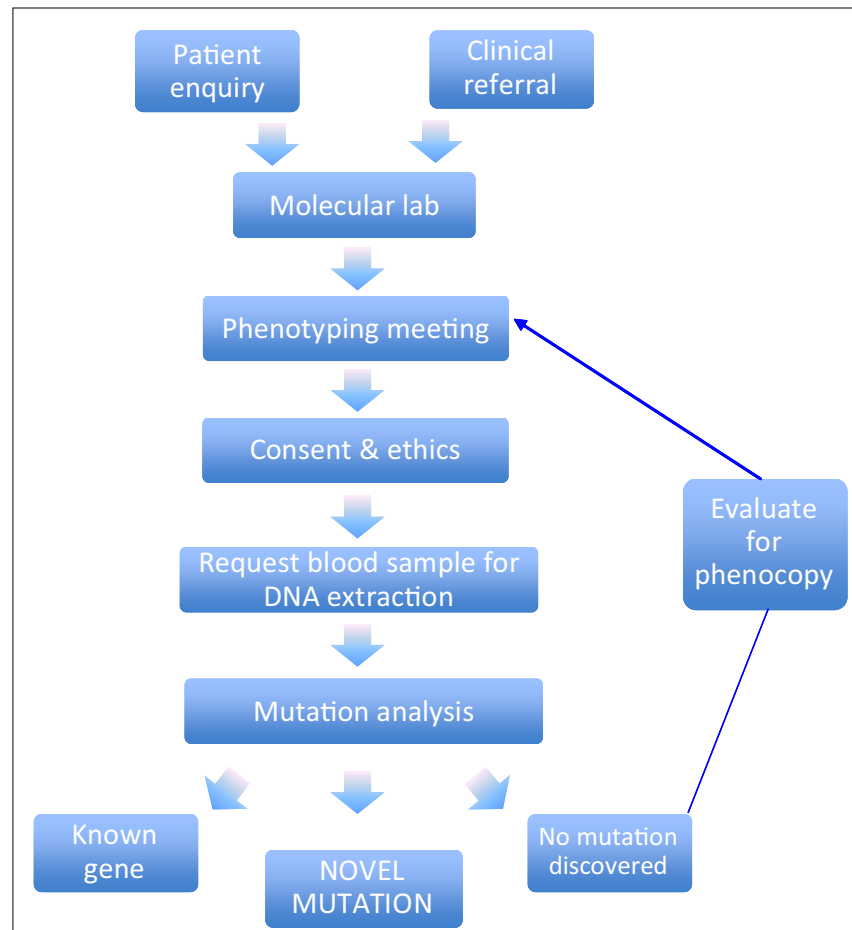

FIGURE 1 | Molecular genetic screening pipeline. This schematic diagram highlights the key stages involved in the clinical ascertainment and molecular genetic diagnosis.

screening in hyperekplexia. In this review, we describe the genetic screening/structure-function approaches utilised in our collaborative group to study hyperekplexia, and discuss future genetic screening approaches for the analysis of this genetically heterogenous neurological disorder.

\section{CLINICAL ASCERTAINMENT OF HYPEREKPLEXIA PATIENTS}

Since 1994, we have received over 260 referrals from clinicians located world-wide to perform genetic testing for hyperekplexia. This is currently performed at the Molecular Neuroscience Laboratory within the Institute of Life Science at Swansea University ${ }^{1}$. Once an anonymous patient clinical summary is received from the referring clinician, data is reviewed by a research committee with a view to assessing whether the patient phenotype fulfils the clinical criteria for mutation screening (Figure 1).

Alternative diagnoses could include paroxysmal extreme pain disorder, startle epilepsy or acquired (autoimmune) hyperekplexia. If the clinical data is suggestive of inherited hyperekplexia then a study information sheet, consent form and clinical pro-forma are issued to the referring clinician. If the patient and/or their family wish to pursue genetic testing on a research basis, then the referring clinician will obtain consent and collect a blood sample. The completed consent form and clinical pro-forma are then returned to the research team along with the blood sample, which is marked with a unique identifier and transferred for extraction of genomic DNA for mutation screening. Details from the clinical pro-forma are then

${ }^{1}$ www.swan.ac.uk/ils incorporated into an anonymous dataset to allow the capture of standardised clinical information for each hyperekplexia sample received. The clinical pro-forma, along with evidence of consent, is stored securely on-site at ILS Swansea.

Since new UK-based ethical approval was confirmed in June 2006 (previous ethical approval in Cardiff University, UK, 1994-1999 and Auckland University, New Zealand, 2000-2006), 41 index patient samples have been accepted for hyperekplexia mutation screening and another 11 are currently undergoing the validation/ascertainment. An additional, 13 familial samples have been received for cascade screening - samples which require verification of identified mutations in close relatives. Testing of parental samples of index cases also enables confirmation of the origin of mutations in cases where compound heterozygosity is suspected.

There are potential risks associated with running an international genetic screening service in this way. Since clinical observations are essential to describe the phenotype of the patients referred to our laboratory, we are dependent upon the detail of information provided by the referring clinicians. Occasionally we receive messages from families, index cases and carers where they have received a clinical diagnosis of hyperekplexia. We strongly believe that giving a genetic diagnosis in the absence of genetic counselling is bad practice, so we encourage these individuals to make contact with us via a clinical referral.

\section{CLINICAL PHENOTYPING OF HYPEREKPLEXIA PATIENTS}

Deciding which patient samples to screen can be challenging. If entry criteria are too narrow then the phenotype is never expanded, too broad and the service can be overwhelmed and yet not produce valuable results (see Table 1). Hyperekplexia is almost certainly a rare condition, but of unknown prevalence and the true phenotype is complicated by cases which report association with co-morbid conditions such as sudden infant death (Giacoia and Ryan, 1994), epilepsy (Lerman-Sagie et al., 2004), abdominal herniae (Eppright and Mayhew, 2007) or developmental delay (Praveen et al., 2001). The early descriptions of hyperekplexia focussed on the shared clinical features (stiffness, startle and falls), the hereditary nature of the condition and the degree of phenotypic variability (which were qualified as 'major' and 'minor' variants) (Kirstein and Silfverskiold, 1958; Kok and Bruyn, 1962). Although many cases were autosomal dominant, this is not exclusively the case and this misconception represents a bias towards studying large families with many affected members (Rees et al., 1994; Masri and Hamamy, 2007). A useful sign particularly in neonatal hyperekplexia (occasionally seen in cerebral palsy) is the nose-tap response: the root of the nose is lightly tapped, provoking a brief and involuntary backwards-retraction of the head.

Neonatal apnoea episodes show an important and potentially life- threatening association with hyperekplexia. These are paroxysmal attacks of abdominal hypertonia with resulting hypoxia. It is important that parents are therefore taught the Vigevano manoeuvre (flexing of the head and limbs toward the trunk) which counteracts these attacks (Vigevano et al., 1989). Whether these hypoxic spells are related to simple intercostal muscle stiffness, brainstem abnormalities or developmental delay remains unknown. 
Table 1 | Diagnostic criteria for human hyperekplexia.

\section{REQUIRED CRITERIA}

Startle: Exaggerated startle reflex to unexpected auditory or tactile stimuli. The startle response can be prolonged and be present before birth.

Consciousness is unaltered during startle episodes. Nose-tap test is positive and does not habituate

Stiffness: Generalized stiffness immediately after birth, normalising during the first years of life. The stiffness can be predominantly truncal or lower limb, increases with handling and disappears during sleep. Short period of generalised stiffness following the startle response during which voluntary movements are impossible. This can result in falls in adults

Exclusion of mimics: Normal MR imaging, no dysmorphism or congenital deficits noted. Normal EEG during startle episode. Autonomic features of paroxysmal extreme pain disorder absent

\section{SUPPORTIVE CRITERIA}

Inguinal, umbilical, or epigastric herniae

Congenital dislocation of the hip

Hypoxic attacks in infancy

\section{THE EFFECT OF PHENOCOPY}

Hyperekplexia is (not unsurprisingly) most commonly confused with seizure disorders (see Table 2) such as benign neonatal convulsions. However, in hyperekplexia, consciousness is retained and there is no EEG correlate to either the startle or hypertonic posturing. False positive results are reported, since exaggerated limb jerking can result in a degree of artefact on the EEG trace. However, symptomatic improvement is often seen with benzodiazepines such as clonazepam and less frequently with other anticonvulsant drug therapies.

Despite the classical features being present from birth or even earlier (some reports suggest that exaggerated startle responses can be felt in utero (Badr El-Din, 1960; Dalla Bernardina et al., 1988; Leventer et al., 1995) the majority of definitive diagnoses are made during infancy. A positive test in an infant can result in older family members receiving an explanation for previously unexplained symptoms. Alternatively, a proportion of early neonatal referrals with primary hypertonia can sometimes develop into more sinister degenerative disorders, which is not typical of inherited hyperekplexia and these cases are invariably negative for GlyR and GlyT2 mutations. However, we are also eager to differentiate between these early onset congenital cases and adult onset cases of hyperekplexia. Since autoimmunity to GlyRs has recently been found in a single case of acquired hyperekplexia (Hutchinson et al., 2008) we can now process samples from such individuals for testing for anti-GlyR or GlyT2 antibodies, using immortalised human cell lines expressing recombinant GlyRs or GlyTs. Hypertonia (predominantly in the lower limbs) is the key presenting feature of stiff-person syndrome, which is associated with either autoimmunity to gephyrin (Butler et al., 2000) orglutamic acid decarboxylase 65 (GAD65; Duddy and Baker, 2009). Furthermore, attempts to definitively describe clinical symptoms and prevalence of hyperekplexia are challenged by potential referral bias. To our knowledge, hyperekplexia has not been diagnosed at the genetic level in people who are ethnically Slavic, South or Central American and very few cases have been reported from Polynesia (see Figure 2). This may be of importance, since there are certain cultural neuropsychiatric conditions such as the 'Jumping Frenchmen of Maine' and 'Latah Syndrome', which share some characteristics with hereditary hyperekplexia (Kurczynski, 1983). Whether these conditions represent the exaggerated startle described in certain anxiety conditions is unknown, since some investigators describe these cultural startle conditions as predominantly psychosomatic in nature (Bartholomew, 1994). Exaggerated startle may also be secondary to predominately pontine pathology: brainstem infarction, infection, haemorrhage or hypoxia can all produce hyperekplexialike symptoms. In addition, individuals with paraneoplastic syndromes, multisystem atrophy and multiple sclerosis can all exhibit exaggerated startle responses (Bakker et al., 2006).

\section{MOLECULAR GENETICS OF HYPEREKPLEXIA}

The most common genetic causes of human hyperekplexia are mutations in the GlyR $\alpha 1$ subunit (GLRA1) and GlyT2 (SLC6A5) genes (see Harvey et al., 2008b for a review and comprehensive mutation data). Therefore, new patient samples that conform to our diagnostic criteria are analysed by PCR amplification of individual exons and dideoxy DNA sequencing on an Applied Biosystems 3100 capillary sequencing platform to detect sequence variants in GLRA1 and SLC6A5 (Rees et al., 2006). For all candidate genes, analysis includes exons and flanking splice branch points, donor and acceptor sequences, $5^{\prime}$ and $3^{\prime}$ untranslated regions and splice variants are derived insilico, using the Human Genome Browser at the University of California, Santa $\mathrm{Cruz}^{2}$. One future aim is also to capture sequence variants in the GLRA1 and SLC6A5 gene promoters, although only the former has been characterised in any detail (Morris et al., 2004), and the minimal promoter encompasses $5.4 \mathrm{~kb}$ of sequence. A robust readout of promoter activity is also required in order to assess any detrimental effect of potential sequence variations. By contrast, GlyT2 transcripts are extensively alternatively spliced at the N-terminus (Ponce et al., 1998; Ebihara et al., 2004), and it is possible that multiple tissue-specific or developmentally regulated promoters exist, complicating potential sequence analysis. Candidate genes with rare or as yet unknown mutation frequencies undergo mediumthroughput gene variation detection by analysing PCR amplimers with a high-resolution melting (HRM) platform (LightScanner, Idaho Technologies, USA). HRM is a highly-sensitive method of analysing genetic variations in short PCR amplicons generated in the presence of the saturating double-stranded DNA binding dye LCGreen ${ }^{\circledR}$ Plus (Idaho Technologies). The technique allows the PCR amplicons to be distinguished based on their dissociation during rapid melting (Figure 3). HRM analysis has a published detection rate of $100 \%$ for heterozygous mutations (Lonie et al., 2006; Kennerson et al., 2007) and has the added advantages of high speed ( $\sim 15$ min per 96 well plate run), no post-PCR handling and greatly reduced costs ( 9 p per amplicon) compared to sequencing ( $\sim \mathfrak{E} 5$ per read from commercial services $)^{3}$. Thus, HRM allows for rapid and cost-effective mutation discovery in dsDNA

\footnotetext{
${ }^{2}$ http://genome.ucsc.edu
}

${ }^{3}$ http://www.dnaseq.co.uk/ 
Table 2 | Clinical phenocopies of human hyperekplexia.

$\begin{array}{ll}\text { Phenocopy Comparisons with human startle } & \text { Compon }\end{array}$

\section{ACQUIRED HYPEREKPLEXIA}

Sub-acute anti-glycine receptor antibody mediated condition that responds to immunosuppression and plasma exchange

(Hutchinson et al., 2008)

\section{PAROXYSMAL EXTREME PAIN DISORDER}

Autosomal dominant condition recently shown to be a sodium channelopathy involving SCN9A (previously known as familial rectal pain syndrome; Fertleman et al., 2007)
Similarities Truncal rigidity, muscle spasms and stimulus induced startle Differences Features not present from early life immunosuppression clearly efficacious. Apnoea attacks not described

\section{JUMPING FRENCHMEN OF MAINE/LATAH SYNDROME}

Culturally bound neuropsychiatric syndromes thought to be an anxiety/somatisation disorder (Meinck, 2006)
Similarities Onset in neonatal period or infancy, persists throughout life. Dramatic syncopes with bradycardia and sometimes asystole.

Tonic attacks are triggered by factors such as defecation, cold wind, eating, and emotion

Differences Autonomic manifestations predominate initially, with skin flushing in all and harlequin colour change. Later attacks of excruciating deep burning pain often in the rectal, ocular, or jaw

Similarities Excessive response to startle

Differences Echopraxia (involuntary repetition of another's words or actions) and echolalia (repetitive vocalisations)

Similarities Surprising stimuli induce motor reactions - consciousness can be preserved in seizures

Differences Neuro-imaging will almost certainly be abnormal

Similarities Stimulus induced hypertonia, startles and falls. Hypertonia can preferentially affect lower-limbs

Differences Stiffness/hypertonia is much more prolonged than the paroxysmal attacks seen in hyperekplexia

\section{TOURETTE'S SYNDROME}

Motor and vocal tics, associated with an exaggerated startle reflex, behaviour change and stereotypy (Bakker et al., 2006)

\section{CRISPONI SYNDROME}

An autosomal recessive syndrome initially described in 12 different families in southern Sardinia; caused by mutations in the CRLF1 gene (Crisponi, 1996; Crisponi et al., 2007)
Similarities Startle response, symptoms precipitate by stressors Differences Vocalisations and obsessive/compulsive behaviours. Motor tics can be complex and appear semi-purposefu

Similarities Evident at birth. Marked muscular contraction of the facial muscles in response to tactile stimuli or during crying, contractions slowly disappear as infant calms. Generalised seizures (albeit rare) and mild psychomotor delay in some. Low GABA levels in CSF have been described Differences Abundant salivation simulating a tetanic spasm. Neck muscle hypertonia. Facial anomalies (large face, chubby cheeks, broad nose with anteverted nostrils and long philtrum). Bilateral camptodactyly. Hyperthermia

Similarities Symptoms will be exaggerated by stressors. Stimulus sensitive (e.g. touch) can be seen following hypoxic brain injury. Children with cerebral palsy may have a positive nose-tap test Differences Acquired cause often clear, for example late adult onset of multi system atrophy. Hypertonia not a feature of anxiety syndromes

\section{SYMPTOMATIC STARTLE AND MYOCLONUS}

\section{Neuropsychiatric - anxiety states including generalised}

anxiety disorder, post traumatic stress disorder

Cerebral - Children with cerebral palsy, post-traumatic or

hypoxic encephalopathy, para neoplastic syndromes

Brainstem - particularly pontine patholog yeg

Multiple system atrophy (Bakker et al., 2006) with improved sensitivity compared to other screening platforms. However, limitations include the optimisation of amplification conditions in the presence of LCGreen ${ }^{\circledR}$ Plus, limitations on the size of amplicons (<400bp) and non-specific amplicons or primer dimers significantly reduce HRM performance. For a comprehensive review of HRM see White and Potts (2006).
PCR products showing variant melting profiles suggestive of allelic heterogeneity undergo purification and direct sequencing to identify the genetic variation. Population studies of genomic variation are performed using agarose gel restriction fragment length polymorphisms (RFLPs) to confirm the absence of the mutation in the healthy population. This can also be confirmed 


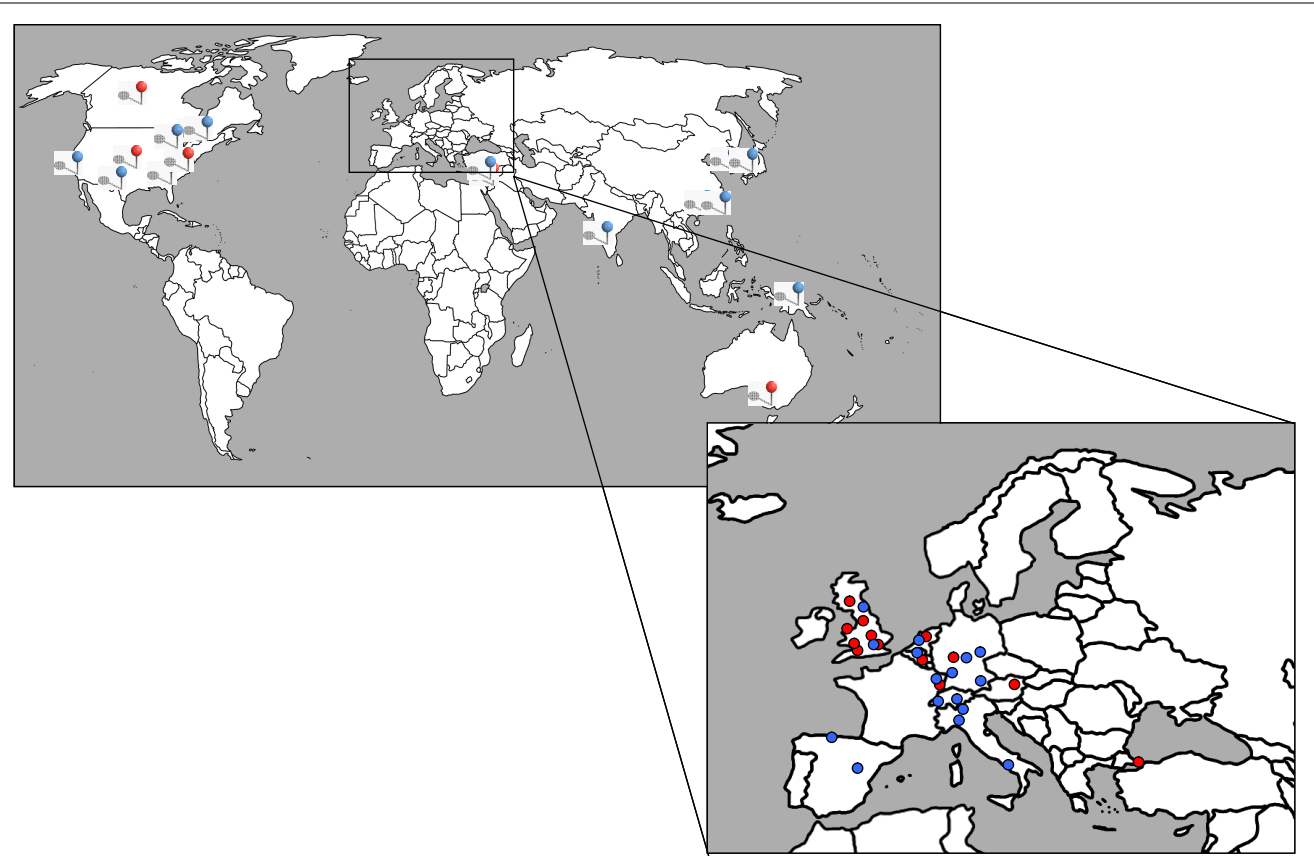

FIGURE 2 | Global origin of hyperekplexia referrals. Upper panel: A geographical representation of the global origin of hyperekplexia patients recruited to our laboratory (red) and other laboratories (blue - Information obtained from the NCBI PubMed search engine). Lower panel: Detail showing the origin of patients recruited from central Europe.

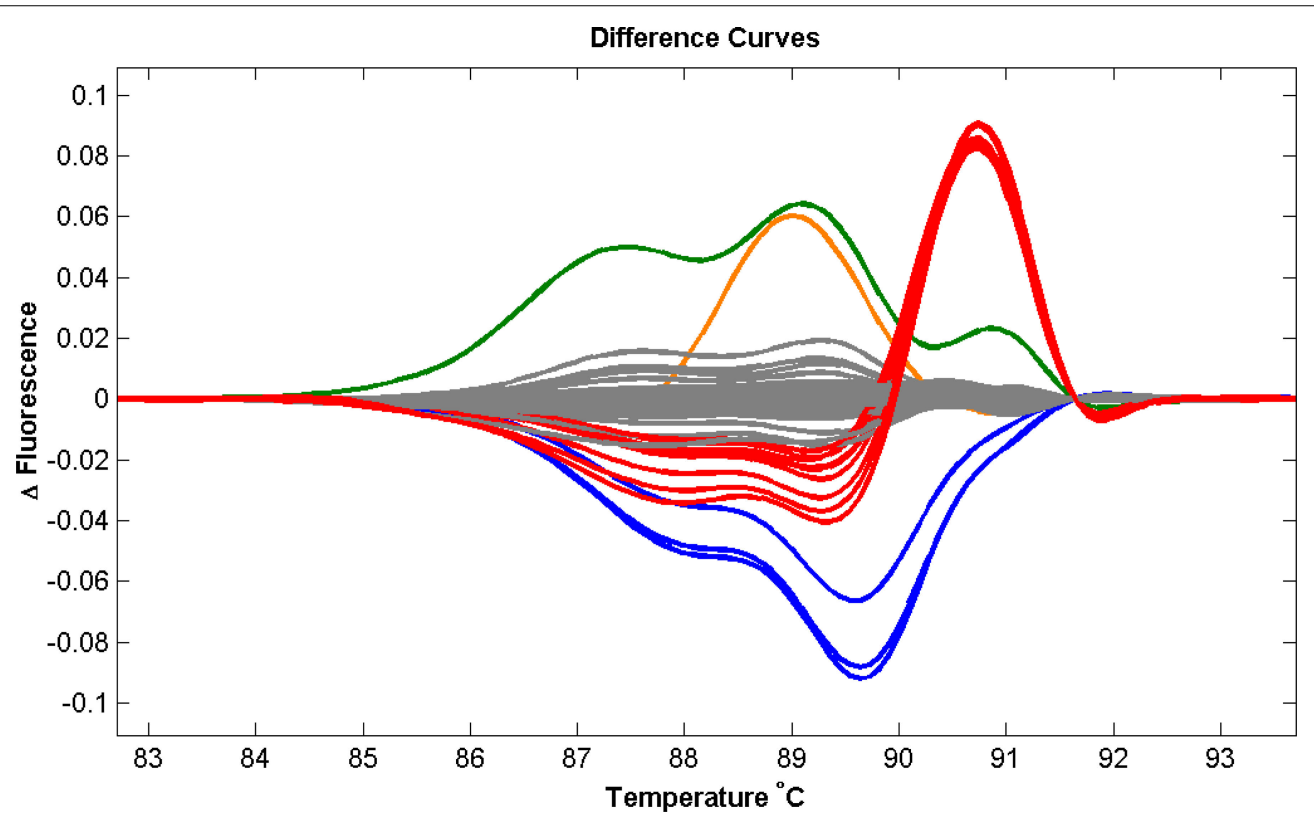

FIGURE 3 | Validation of the Light Scanner technology. To assess the application of this method we performed a series of validation assays utilising known genetic variations in the GLRA1 gene in a population of hyperekplexia patients. This screening method accurately detected all heterozygous (red and orange) and homozygous (blue) missense mutations present. The most common GLRA1 mutation associated with hyperekplexia, R271Q, is shown in red. The assay also detected a false-positive variant (green) generated due to the poor quality of amplified PCR product. Population control samples are shown in grey. byassessing HRM profiles of control DNA samples alongside a mutation-positive sample. DNA sequencing chromatograms are then assessed using an automated mutation surveyor programme
(MutationSurveyor, SoftGenetics ${ }^{\circledR}$, USA) which is particularly useful for detecting homozygous changes in the sequence data. After this systematic analysis in our laboratory, 53 single, unrelated, 
sporadic cases of hyperekplexia have proved gene-negative in screening approaches for GLRA1, GLRB, GPHN, ARHGEF9 and SLC6A5.

Both dominant and recessive mutations in GLRA1 are associated with sporadic and familial startle disease, whilst a proportion of sporadic hyperekplexia is accounted for by the homozygous inheritance of recessive or compound heterozygous GLRA1 mutations (Rees et al., 2001). By contrast, the vast majority of mutations in SLC6A5 are inherited as compound heterozygotes or show recessive inheritance of a single mutation from consanguineous parents. To date, there is only a single example of a dominant mutation in SLC6A5 (Rees et al., 2006). Hence, the parental carriers of SLC6A5 mutations are typically asymptomatic indicating that dominant negative effects are not a common mutational mechanism. Other explanations for a single mutation could include an undetected second-hit event, not easily detectable by PCR and sequencing. For example, promoter mutations, large deletions or intronic SNPs causing allelic dropout due to PCR primer mismatches are possible. Even synonymous SNPs that do not cause an amino acid substitution could cause creation of an ectopic splice donor or acceptor site, causing missplicing of gene transcripts. We have begun to assess these issues by using multiplex ligation-dependent probe amplification (MLPA) analysis in index cases, to assay for possible deletions in SLC6A5 and GLRA1. MLPA provides the means for the quantitative analysis of various changes in gene structure and/or gene copy number of several dozens (40-50) of DNA targets in a single reaction containing small amounts ( 20ng) of human chromosomal DNA. Binary probes containing a sequence-specific part and a universal part are hybridized to their DNA targets and ligated. Each ligated probe is then PCR amplified with a universal primer pair and gives rise to an amplicon of unique size. The relative amount of each amplicon reflects the quantity of the corresponding target that is present in the nucleic acid sample. While allelic drop-out can be assessed by designing an additional primer set, changes in the promoter sequences and splicing patterns of GLRA1 and SLC6A5 are more challenging. In particular, we are also limited by the lack of patientspecific RNA resource or the assurance that the genes are expressed in peripheral leukocytes. Affordable next generation re-sequencing (e.g. 454 Roche, Illumina Solexa, AB SOLiD) along with highthroughput splicing assays may resolve these current limitations. These resources would also allow us to assess changes in RNA editing of GlyR transcripts, an important consideration for studies of GlyR $\alpha 2$ and $\alpha 3$ subunit genes in health and disease (Meier et al., 2005; Eichler et al., 2009).

\section{MOLECULAR ANALYSIS OF POTENTIALLY PATHOGENIC MUTATIONS}

Potentially disease-causing mutations can also be subjected to functional and molecular modelling analysis to provide insight into the precise mechanisms underlying pathogenicity. In the case of SLC6A5, mutations were analysed by homology modelling of GlyT2 using the crystal structure of the bacterial leucine transporter (LeuT) (Yamashita et al., 2005). Simple sequence alignments of LeuT with GlyT1 and GlyT2 allowed us to identify residues potentially involved in coordinating glycine and $\mathrm{Na}^{+}$binding (Rees et al., 2006), which were later confirmed by assays on recombinant wild-type and mutant GlyT2 including $\left[{ }^{3} \mathrm{H}\right]$ glycine uptake assays, sophisticated electrophysiological analyses in Xenopus oocytes and molecular modelling (Rees et al., 2006; Harvey et al., 2008a).

Structural modelling is carried out using a homology modelling pipeline built with the Biskit structural bioinformatics platform (Grunberg et al., 2007). Our pipeline workflow incorporates the NCBI tools platform (Wheeler et al., 2007), including the BLAST program (Altschul et al., 1990) for similarity searching of sequence databases. Protein sequences corresponding to the Protein Databank of protein structures were searched for homology with the gene of interest in order to identify putative structural homologues. T-COFFEE (Notredame et al., 2000) was used for alignment of the test sequence with the template, followed by 10 iterations of the MODELLER homology modelling program (Eswar et al., 2003) (Figure 4).

\section{FURTHER HYPEREKPLEXIA CANDIDATE GENES}

Our recent research into glycinergic transmission has clearly demonstrated the importance of both presynaptic (GlyT2) and postsynaptic (GlyR $\alpha 1 \beta)$ mechanisms in health and disease. This work has also suggested that our search for other suitable candidate genes for mutation analysis in human hyperekplexia should be broadened (Table 3). Potential target genes are discussed below in the context of their putative roles in glycinergic synaptic physiology.

\section{GlyT1}

Whilst inhibitory glycinergic neurotransmission is dependent upon agonist-mediated activation of postsynaptic GlyRs, this function is dependent upon having a sufficient pool of releasable glycine within the presynaptic terminal and prompt termination of glycinergic transmission. GlyT1, encoded by SLC6A9 (1p34.1) fulfils the latter function, and is predominately expressed on glial cells. Studies on GlyT1 knockout mice (Gomeza et al., 2003b; Tsai et al., 2004) suggest that loss of function of GlyT1 results in a pathological accumulation of synaptic glycine, causing severe motor deficits and premature death as a result of respiratory failure. The phenotype of the GlyT1 knockout mouse resembles a devastating neurological disorder known as glycine encephalopathy (OMIM 605899) although no SLC6A9 mutations have been found to date in this disorder in humans. However, it is possible that more subtle missense mutations could result in a gain of function of GlyT1, causing enhanced clearance of glycine from the synaptic cleft into neighbouring glial cells. This could cause depletion of glycine in neighbouring presynaptic neurones, which may result in hyperekplexia in humans (Harvey et al., 2008a).

\section{GlyT2 INTERACTORS}

Further presynaptic candidates for genetic analysis include proteins interacting with GlyT2, such as syntenin-1 and ULIP6. ULIP6 is encoded by DPYSL5 (2p23.3) and is a brain-specific phosphoprotein of the Ulip/collapsing response mediator protein family. ULIP6 interacts with extended intracellular N-terminus of GlyT2 in a phosphorylation dependent manner (Horiuchi et al., 2005). Since ULIP6 has been implicated in GlyT2 endocytosis and recycling (Eulenburg et al., 2005; Horiuchi et al., 2005), it is plausible that mutations in ULIP6 could cause hyperekplexia by altering levels of presynaptic GlyT2. By contrast, the PDZ containing protein syntenin-1, encoded 
A

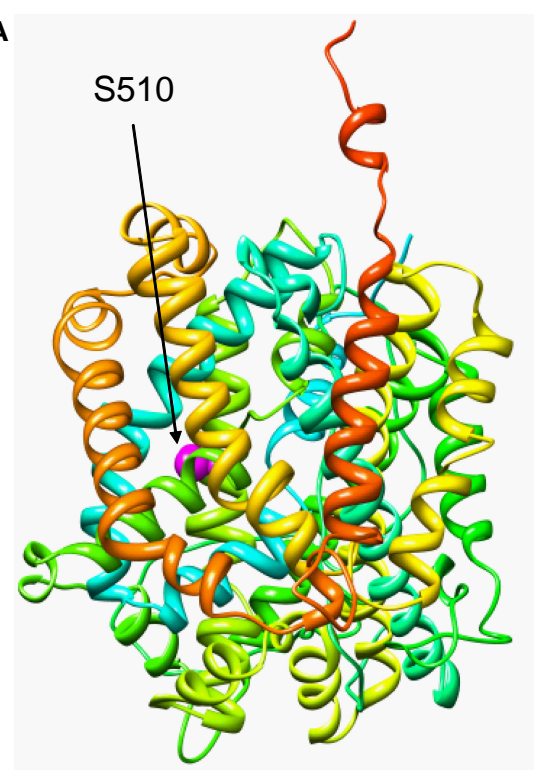

FIGURE 4 | Structural modelling of human GlyT2. The wild-type (A) and the S510R mutant (B) model were generated based on homology with the crystal structure of LeuT, a bacterial $\mathrm{Na}^{+} / \mathrm{Cl}^{-}$-dependent neurotransmitter transporter homologue (PDB: 2A65). The models cover residues 191-754 of GlyT2 and show the position of the S510R mutation in TM7 along with

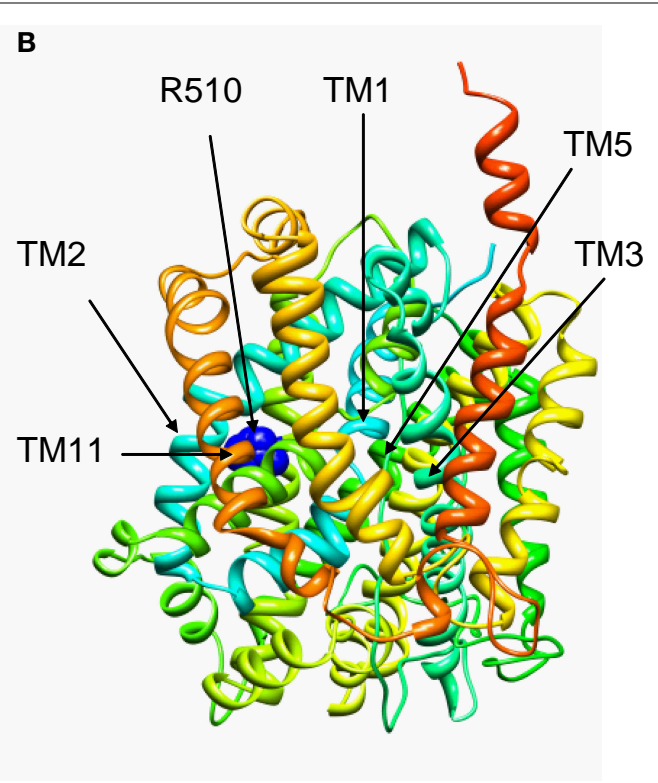

the extensive re-arrangement of other transmembrane regions in the S510R that results in defective membrane trafficking of S510R and trapping of wild-type GlyT2 (see Rees et al., 2006). Models were visualized using the molecular graphics program Chimera (http://www.cgl.ucsf.edu/ chimera/).
Table 3 | Candidate genes for mutation screening in hyperekplexia. Chromosomal locations were obtained from http://ncbi.nlm.nih.gov/

\begin{tabular}{llll}
\hline Candidate gene & Location & Protein & $\begin{array}{l}\text { Proposed role at } \\
\text { glycinergic synapse }\end{array}$ \\
\hline SLC6A9 & $1 \mathrm{p} 34.1$ & GlyT1 & $\begin{array}{l}\text { Termination of glycinergic } \\
\text { neurotransmission by }\end{array}$ \\
& $20 \mathrm{q} 11.23$ & VIAAT & $\begin{array}{l}\text { Vesicular transport of GABA } \\
\text { Vesto glial cells }\end{array}$ \\
SLC32A1 & $1 \mathrm{p} 13.3$ & NTT4 & $\begin{array}{l}\text { Vesicular transport of glycine } \\
\text { GlyT2 interacting protein }\end{array}$ \\
SLC6A17 & $2 \mathrm{p} 23.3$ & ULIP6 & GlyT2 interacting protein \\
DPYSL5 & $8 \mathrm{q} 12.1$ & Syntenin-1 & Gly \\
\hline SDCBP & & & \\
\hline
\end{tabular}

by the gene SDCBP $(8 \mathrm{q} 12.1)$ is thought to regulate the trafficking or presynaptic localisation of GlyT2 in glycinergic neurones (Ohno et al., 2004). Mutations that affect syntenin PDZ binding domains could cause mislocalisation of GlyT2 and other interacting partners, since GlyT2 localisation in the presynaptic terminal is dependent on the C-terminal PDZ binding motif (Armsen et al., 2007). However, due to the wide range of proteins interacting with syntenin-1, we consider it unlikely that defects in syntenin-1 will give rise to classical hyperekplexia (Harvey et al., 2008b).

\section{VIAAT}

Another obvious hyperekplexia candidate gene is the vesicular inhibitory amino acid transporter (VIAAT), encoded by SLC32A1 (20q11.23). VIAAT is expressed in both GABAergic and glycinergic neurones (Chaudhry et al., 1998), and is responsible for the chloride-dependent loading of presynaptic vesicles with GABA and glycine (Jin et al., 2003; Juge et al., 2009). We suggest that certain mutations in VIAAT could lead to the specific loss of glycine (but not GABA) loading into synaptic vesicles, thus resulting in hyperekplexia. VIAAT was first identified as a mammalian homologue of the 'uncoordinated' C. elegans mutant unc-47, which was known to be defective in a presynaptic component of GABA release. Despite the fact that $C$. elegans do not appear to use glycine as a neurotransmitter, in a sophisticated cellular assay Aubrey et al. (2007) were able to show that UNC-47 is able to readily transport both GABA and glycine into vesicles. Importantly, the UNC-47 mutation G462R was shown to abolish GABA, but not glycine uptake. Since residue G462 is conserved at the equivalent position (G500) in rodent and human VIAAT sequences, mutations in SLC32A1 could theoretically compromise GABA uptake into synaptic vesicles while leaving glycine uptake intact. Since it is clearly possible to separate GABA and glycine transport by a single missense mutation, our hypothesis is that other missense mutations could also result in a GABA-specific VIAAT, potentially resulting in hyperekplexia.

\section{NTT4}

The orphan transporter NTT4 (also known as Rxt1), encoded by SLC6A17 (1p13.3) has recently been implicated as a vesicular transporter for glycine, proline, leucine and alanine (Parra et al., 2008). This novel finding suggests that NTT4, which is highly expressed in several brain regions, including the spinal cord (Liu et al., 1993), may have an important role in glycinergic transmission and possibly hyperekplexia. 


\section{THE FUTURE - PHENOTYPING, GENOMIC AND PROTEOMIC REVOLUTION}

Despite the advances in the molecular genetics of hyperekplexia of the last 20 years, we are no closer to describing certain clinical aspects than the original pioneering study by Andermann et al. (1980). Hyperekplexia is rare, easily misdiagnosed and clonazepam is still the current treatment of choice. We have been unable to find a genetic basis to the original delineation - the so called 'major' and 'minor' variants. Collections of large cohorts, particularly containing sporadic cases may help us move away from the inherent bias caused by studying large families with a single gene mutation. Future challenges include improving testing turnaround times and accessibility, and collecting comprehensive clinical data to improve our understanding of possible differences in clinical phenotypes caused by mutations in GLRA1 versus SLC6A5. This will also enable us to identify potential hyperekplexia-associated co-morbidities and identify potential phenocopy referrals.

On the horizon is the prospect of third generation sequence platforms which will facilitate automated re-sequencing of large genomic segments containing disease-causing genes and new candidate loci and possibly even whole genomes of affected individuals. These include the pyrosequencing-based platform of next generation 454 sequencing (see Rothberg and Leamon, 2008) which was recently used for rapid genome re-sequencing of an individual genome at a fraction of the cost of previous platforms (Wheeler et al., 2008). Such coverage will provide not only the sequence of coding exons and flanking spice sites, but information on intragenic DNA, SNP haplotype risk factors and copy number variables. Affordability is at present the main barrier and as a medium-term solution enrichment of individual chromosomal regions containing
GLRA1 and SLC6A5 may provide an interim solution. For example, Zheng and colleagues have recently developed a method for highthroughput variant detection, utilising specific genomic regions for target amplification by capture and ligation (TACL), allele enrichment and array resequencing (Zheng et al., 2009). This platform has identified rare and novel variants, and will undoubtedly lead to improvements in our understanding of complex genetic disorders.

Molecular biology, animal models of glycinergic function and detailed proteomic studies will continue to provide further candidates for genetic screening in hyperekplexia and other potential disorders of glycinergic synapses. The new targets described above are being screened at present in patients lacking mutations in GLRA1 and SLC6A5. Molecular genetic studies of unresolved ENU-induced mutations in zebrafish (Granato et al., 1996) may also tease out novel determinants of glycinergic function (Hirata et al., 2010). These leads suggest that new genes of major effect could shortly join GLRA1 and SLC6A5 in our molecular screening programme.

\section{ACKNOWLEDGMENTS}

The clinical ascertainment aspects described in this review were reviewed and approved by the Local Research Ethics Committee, the South West Wales REC. Research on hyperekplexia in our laboratories is supported by grants from the Medical Research Council (G0601585 to Robert J. Harvey, Kirsten Harvey and Mark I. Rees) and the Wales Office of Research and Development (Wales Epilepsy Research Network to Mark I. Rees). We would also like to thank Jean-Francois Vanbellinghen (University of Liege, Belgium) for providing information for Figure 2.

\section{REFERENCES}

Altschul, S. F., Gish, W., Miller, W. Myers, E. W., and Lipman, D. J. (1990). Basic local alignment search tool. J. Mol. Biol. 215, 403-410.

Andermann, F., Keene, D. L. Andermann, E., and Quesney, L. F. (1980). Startle disease or hyperekplexia: further delineation of the syndrome. Brain 103, 985-997.

Armsen, W., Himmel, B., Betz, H., and Eulenburg, V. (2007). The C-terminal PDZ-ligand motif of the neuronal glycine transporter GlyT2 is required for efficient synaptic localization. $\mathrm{Mol}$. Cell. Neurosci. 36, 369-380.

Aubrey, K. R., Rossi, F.M., Ruivo, R.,Alboni, S., Bellenchi, G. C., Le Goff, A., Gasnier, B., and Supplisson, S. (2007). The transporters GlyT2 and VIAAT cooperate to determine the vesicular glycinergic phenotype. J. Neurosci. 27, 6273-6281.

Badr El-Din, M. K. (1960). A familial convulsive disorder with an unusual onset during intrauterine life: a case report. J. Pediatr. 56, 655-657.

Bakker, M. J., van Dijk, J. G., van den Maagdenberg, A. M., and Tijssen, M. A. (2006). Startle syndromes. Lancet Neurol. 5, 513-524.
Bartholomew, R. E. (1994). Disease, disorder or deception? Latah as habit in a Malay extended family. J. Nerv. Ment. Dis. 182, 331-338.

Becker, C.-M., Schmieden, V., Tarroni, P., Strasser, U., and Betz, H. (1992). Isoform-selective deficit of glycine receptors in the mouse mutant spastic. Neuron 8, 283-289.

Buckwalter, M. S., Cook, S. A., Davisson, M. T., White, W. F., and Camper, S. A. (1994). A frameshift mutation in the mouse $\alpha 1$ glycine receptor gene (GLRA1) results in progressive neurological symptoms and juvenile death. Hum. Mol. Genet. 3, 2025-2030.

Butler, M. H., Hayashi, A., Ohkoshi, N., Villmann, C., Becker, C.-M., Feng, G., De Camilli, P., and Solimena, M. (2000). Autoimmunity to gephyrin in stiff-man syndrome. Neuron 26, 307-312.

Chaudhry, F. A., Reimer, R. J., Bellocchio, E. E., Danbolt, N. C., Osen, K. K., Edwards, R. H., and Storm-Mathisen, J. (1998). The vesicular GABA transporter, VGAT, localises to synaptic vesicles in sets of glycinergic as well as GABAergic neurons. J. Neurosci. 18, 9733-9750.
Crisponi, G. (1996). Autosomal recessive disorder with muscle contractions resembling neonatal tetanus, characteristic face, camptodactyly, hyperthermia, and sudden death: a new syndrome? Am. J. Med. Genet. 62, 365-371.

Crisponi, L., Crisponi, G., Meloni, A. Toliat, M. R., Nurnberg, G., Usala, G., Uda, M., Masala, M., Hohne, W. Becker, C., Marongiu, M., Chiappe, F., Kleta, R., Rauch, A., Wollnik, B., Strasser, F., Reese, T., Jakobs, C., Kurlemann, G., Cao, A., Nurnberg, P., and Rutsch, F. (2007). Crisponi syndrome is caused by mutations in the CRLF1 gene and is allelic to coldinduced sweating syndrome type 1 . Am. J. Hum. Genet. 80, 971-981.

Dalla Bernardina, B., Fontana, E., Colamaria, V., La Selva, L., Merlin, D., Sgrò, V., and Scarpa, P. (1988) "Neonatal hyperexplexia," in Reflex Seizures and Reflex Epilepsy, eds A. Beaumanoir, H. Gastaut and R. Naquet (Geneve: Editions Medicine and Hygiene), 409-414.

Duddy, M. E., and Baker, M. R. (2009). Stiff person syndrome. Front. Neurol. Neurosci. 26, 147-165.
Ebihara, S., Yamamoto, T., Obata, K., and Yanagawa, Y. (2004). Gene structure and alternative splicing of the mouse glycine transporter type-2. Biochem. Biophys. Res. Commun. 317, 857-864.

Eichler, S. A., Förstera, B., Smolinsky, B., Jüttner, R., Lehmann, T. N., Fähling, M., Schwarz, G., Legendre, P., and Meier, J. C. (2009). Splice-specific roles of glycine receptor $\alpha 3$ in the hippocampus. Eur. J. Neurosci. 30, 1077-1091.

Eppright, B., and Mayhew, J. F. (2007). Bilateral inguinal hernia repair in a child with hyperekplexia. Paediatr. Anaesth. 17, 1099-1101.

Eswar, N., John, B., Mirkovic, N., Fiser, A., Ilyin, V. A., Pieper, U., Stuart, A. C., Marti-Renom, M. A., Madhusudhan, M. S., Yerkovich, B., and Sali, A. (2003). Tools for comparative protein structure modeling and analysis. Nucleic Acids Res. 31, 3375-3380.

Eulenburg, V., Armsen, W., Betz, H., and Gomeza, J. (2005). Glycine transporters: essential regulators of neurotransmission. Trends Biochem. Sci. 30, 325-333. 
Eulenburg, V., Becker, K., Gomeza, J., Schmitt, B., Becker, C. M., and Betz, H. (2006). Mutations within the human GLYT2 (SLC6A5) gene associated with hyperekplexia. Biochem. Biophys. Res. Commun. 348, 400-405.

Fertleman, C. R., Ferrie, C. D., Aicardi, J., Bednarek, N. A., Eeg-Olofsson, O., Elmslie, F. V., Griesemer, D. A., Goutières, F., Kirkpatrick,M.,Malmros, I. N., Pollitzer, M., Rossiter, M., RouletPerez, E., Schubert, R., Smith, V. V., Testard, H., Wong, V., and Stephenson, J. B. (2007). Paroxysmal extreme pain disorder (previously familial rectal pain syndrome). Neurology 69, 586-595.

Giacoia, G. P., and Ryan, S. G. (1994). Hyperekplexia associated with apnea and sudden infant death syndrome. Arch. Pediatr. Adolesc. Med. 148, 540-543.

Gomeza, J., Ohno, K., Hülsmann, S., Armsen, W., Eulenburg, V., Richter, D. W., Laube, B., and Betz, H. (2003a). Deletion of the mouse glycine transporter 2 results in hyperekplexia phenotype and postnatal lethality. Neuron $40,797-806$

Gomeza, J., Hülsmann, S., Ohno, K., Eulenburg, V., Szöke, K., Richter, D., and Betz, H. (2003b). Inactivation of the glycine transporter 1 gene discloses vital role of glial glycine uptake in glycinergic inhibition. Neuron 40, 785-796.

Granato, M., van Eeden, F. J., Schach, U., Trowe, T., Brand, M., Furutani-Seiki, M., Haffter, P., Hammerschmidt, M., Heisenberg, C. P., Jiang, Y. J., Kane, D. A., Kelsh, R. N., Mullins, M. C., Odenthal, J., and Nüsslein-Volhard, C. (1996). Genes controlling and mediating locomotion behavior of the zebrafish embryo and larva. Development 123, 399-413.

Grudzinska, J., Schemm, R., Haeger, S., Nicke, A., Schmalzing, G., Betz, H., and Laube, B. (2005). The beta subunit determines the ligand binding properties of synaptic glycine receptors. Neuron 45, 727-739.

Grunberg, R., Nilges, M., and Leckner, J. (2007). Biskit - a software platform for structural bioinformatics. Bioinformatics 23, 769-770.

Harvey, K., Duguid, I. C., Alldred, M. J., Beatty, S. E., Ward, H., Keep, N. H., Lingenfelter, S. E., Pearce, B. R., Lundgren, J., Owen, M. J., Smart, T. G., Lüscher, B., Rees, M. I., and Harvey, R. J. (2004). The GDP-GTP exchange factor collybistin: an essential determinant of neuronal gephyrin clustering. J. Neurosci. 24, 5816-5826.

Harvey, R. J., Topf, M., Harvey, K., and Rees, M. I. (2008a). The genetics of hyperekplexia: more than startle! Trends Genet. 24, 439-447.

Harvey, R. J., Carta, E., Pearce, B. R., Chung, S. K., Supplisson, S., Rees, M.I., and Harvey, K. (2008b). A critical role for glycine transporters in hyperexcitability disorders. Front. Mol. Neurosci. $1,1-6$.

Hirata, H., Carta, E., Yamanaka, I. Harvey, R. J., and Kuwada, J. Y. (2010). Defective glycinergic synaptic transmission in zebrafish motility mutants. Front. Mol. Neurosci. 2:26. doi:10.3389/neuro.02.026.2009.

Hirata, H., Saint-Amant, L., Downes, G. B., Cui, W. W., Zhou, W., Granato, M., and Kuwada, J. Y. (2005). Zebrafish bandoneon mutants display behavioral defects due to a mutation in the glycine receptor beta-subunit. Proc. Natl. Acad. Sci. U.S.A. 102, 8345-8350.

Horiuchi, M., Horiuchi, M., Loebrich, S., Brandstaetter, J. H., Kneussel, M. and Betz, H. (2005). Cellular localisation and subcellular distribution of Unc-33-like protein 6, a brain-specific protein of the collapsin response mediator protein family that interacts with the neuronal glycine transporter 2. J. Neurochem. 94, 307-315.

Hutchinson, M., Waters, P., McHugh, J., Gorman, G., O'Riordan, S., Connolly, S., Hager, H., Yu, P., Becker, C. M., and Vincent, A. (2008). Progressive encephalomyelitis, rigidity, and myoclonus: a novel glycine receptor antibody. Neurology 71, 1291-1292.

Jin, H., Wu, H., Osterhaus, G., Wei, J., Davis, K., Sha, D., Floor, E., Hsu, C. C., Kopke R. D., and Wu, J. Y. (2003). Demonstration of functional coupling between $\gamma$-aminobutyric acid (GABA) synthesis and vesicular GABA transport into synaptic vesicles. Proc. Natl. Acad. Sci. U.S.A. 100, 4293-4298.

Juge, N., Muroyama, A., Hiasa, M., Omote, H., and Moriyama, Y. (2009). Vesicular inhibitory amino acid transporter is a $\mathrm{Cl}-/ \gamma$-aminobutyrate co-transporter. $J$. Biol. Chem. 284, 35073-35078.

Kalscheuer, V. M., Musante, L., Fang, C., Hoffmann, K., Fuchs, C., Carta, E., Deas, E., Venkateswarlu, K., Menzel, C., Ullmann, R., Tommerup, N., Dalprà, L., Tzschach, A., Selicorni, A., Lüscher, B., Ropers, H. H., Harvey, K., and Harvey, R. J. (2009). A balanced chromosomal translocation disrupting ARHGEF9 is associated with epilepsy, anxiety, aggression, and mental retardation. Hum. Mutat. 30, 61-68.

Kennerson, M. L., Warburton, T., Nelis, E., Brewer, M., Polly, P., De Jonghe, P., Timmerman, V., and Nicholson, G. A. (2007). Mutation scanning the GJB1 gene with high-resolution melting analysis: implications for mutation scanning of genes for Charcot-Marie-Tooth disease. Clin. Chem. 53, 349-352.

Kingsmore,S.F., Giros, B., Suh,D., Bieniarz, M., Caron, M. G., and Seldin, M. F. (1994). Glycine receptor $\beta$ subunit gene mutation in spastic mouse associated with LINE-1 element insertion. Nat. Genet. 7, 136-141.

Kirstein, L., and Silfverskiold, B. P. (1958). A family with emotionally precipitated 'drop seizures'. Acta. Psychiatr. Neurol. Scand. 33, 471-476.

Kok, O., and Bruyn, G. W. (1962). An unidentified hereditary disease. Lancet 1 , 1359.

Kurczynski, T. W. (1983). Hyperekplexia. Arch. Neurol. 40, 246-248.

Lerman-Sagie, T., Watemberg, N., Vinkler, C., Fishhof, J., Leshinsky-Silver, E., and Lev,D.J.(2004).Familial hyperekplexia and refractory status epilepticus: a new autosomal recessive syndrome. J. Child Neurol. 19, 522-525.

Leventer, R. J., Hopkins, I. J., and Shield, L. (1995). Hyperekplexia as cause of abnormal intrauterine movements. Lancet 345, 461.

Liu, Q. R., Mandiyan, S., Lopez-Corcuera, B., Nelson, H., and Nelson, N. (1993) A rat brain cDNA encoding the neurotransmitter transporter with an unusual structure. FEBS Lett. 315 , 114-118.

Lonie, L., Porter, D. E., Fraser, M., Cole, T., Wise, C., Yates, L., Wakeling, E., Blair, E., Morava, E., Monaco, A. P., and Ragoussis, J. (2006). Determination of the mutation spectrum of the EXT1/EXT2 genes in British Caucasian patients with multiple osteochondromas, and exclusion of six candidate genes in EXT negative cases. Hum. Mutat. 27, 1160 .

Lynch, J. L. (2009). Native glycine receptor subtypes and their physiological roles. Neuropharmacology 56, 303-309.

Marco,E.J.,Abidi,F.E., Bristow,J.,Dean,W. B., Cotter, P., Jeremy, R. J., Schwartz, C. E., and Sherr, E. H. (2008). ARHGEF9 disruption in a female patient is associated with X-linked mental retardation and sensory hyperarousal.J. Med. Genet. 45, 100-105.

Masri, A. T., and Hamamy, H. A. (2007) Clinical and inheritance profiles of hyperekplexia in Jordan. J. Child Neurol. 22, 895-900.

Meier, J. C., Henneberger, C., Melnick, I., Racca, C., Harvey, R. J., Heinemann, U., Schmieden, V., and Grantyn, R. (2005). RNA editing produces glycine receptor alphaP185L, resulting in high agonist potency. Nat. Neurosci. 8, 736-744.

Meinck, H. M. (2006). Startle and its disorders. Clin. Neurophysiol. 36 357-364.

Morris, R., Morgan, B. S., Lewis, T. M., Pierce, K.D., Pisano, A., and Schofield, P. R. (2004). In vivo somatic delivery of plasmid DNA and retrograde transport to obtain cell-specific gene expression in the central nervous system. J. Neurochem. 90, 1445-1452.
Mülhardt, C., Fischer, M., Gass, P., SimonChazottes, D., Guénet, J. L., Kuhse, J., Betz,H., and Becker, C.M. (1994). The spastic mouse: aberrant splicing of glycine receptor $\beta$ subunit mRNA caused by intronic insertion of L1 element. Neuron 13, 1003-1015.

Notredame, C., Higgins, D. G., and Heringa, J. (2000). T-Coffee: a novel method for fast and accurate multiple sequence alignment. J. Mol. Biol. 302, 205-217.

Ohno, K., Koroll, M., El Far, O., Scholze, P., Gomeza, J., and Betz, H. (2004). The neuronal glycine transporter 2 interacts with the PDZ-binding domain protein syntenin-1.Mol. Cell. Neurosci. 26, 518-529.

Parra, L. A., Baust, T., Mestikawy, S. E., Quiroz, M., Hoffman, B., Haflett, J. M., Yao, J. K., and Torres, G. E. (2008). The orphan transporter RXT1/NTT4 (SLC6A17) functions as a synaptic vesicle amino acid transporter selective for proline, glycine, leucine, and alanine. Mol. Pharmacol. 74, 1521-1532.

Ponce, J., Poyatos, I., Aragón, C., Jiménez, C., and Zafra, F. (1998). Characterization of the 5 ' region of the rat brain glycine transporter GLYT2 gene: identification of a novel isoform Neurosci. Lett. 242, 25-28.

Praveen, V., Patole, S. K., and Whitehall, J. S. (2001). Hyperekplexia in neonates. Postgrad. Med. J. 77, 570-572.

Rees, M. I., Andrew, M., Jawad, S., and Owen, M. J. (1994). Evidence for recessive as well as dominant forms of startle disease (hyperekplexia) caused by mutations in the $\alpha 1$ subunit of the inhibitory glycine receptor. Hum. Mol. Genet. 3, 2175-2179.

Rees, M. I., Harvey, K., Pearce, B. R., Chung, S. K., Duguid, I. C., Thomas, P., Beatty, S., Graham, G. E., Armstrong, L., Shiang, R., Abbott, K. J., Zuberi, S. M., Stephenson, J. B., Owen, M. J., Tijssen, M. A., van den Maagdenberg, A. M., Smart, T. G., Supplisson, S., and Harvey, R. J. (2006). Mutations in the GlyT2 gene define a presynaptic component of human startle disease. Nat. Genet. 38, 801-806

Rees, M. I., Harvey, K., Ward, H., White, J. H., Evans, L., Duguid, I. C., Hsu, C. C., Coleman, S. L., Miller, J., Baer, K., Waldvogel, H. J., Gibbon, F., Smart, T. G., Owen, M. J., Harvey, R. J., and Snell, R. G. (2003). Isoform heterogeneity of the human gephyrin gene (GPHN), binding domains to the glycine receptor, and mutation analysis in hyperekplexia. J. Biol. Chem. 278, 24688-24696.

Rees, M. I., Lewis, T. M., Kwok, J. B., Mortier, G. R., Govaert, P., Snell, R. G., Schofield, P. R., and Owen, M. J. (2002). Hyperekplexia associated with compound heterozygote mutations in 
the $\beta$ subunit of the human inhibitory glycine receptor (GLRB). Hum. Mol. Genet. 11, 853-860.

Rees, M. I., Lewis, T. M., Vafa, B., Ferrie, C., Corry, P., Muntoni, F., Jungbluth, H., Stephenson, J. B., Kerr, M., Snell, R. G., Schofield, P. R., and Owen, M. J. (2001). Compound heterozygosity and nonsense mutations in the $\alpha 1$ subunit of the inhibitory glycine receptor in hyperekplexia. Hum. Genet. 109, 267-270.

Reiss, J., Gross-Hardt, S., Christensen, E., Schmidt,P., Mendel, R. R., and Schwarz, G. (2001).A mutation in the gene for the neurotransmitter receptor-clustering protein gephyrin causes a novel form of molybdenum cofactor deficiency. Am. J. Hum. Genet. 68, 208-213.

Rothberg, J. M., and Leamon, J. H. (2008). The development and impact of 454 sequencing. Nat. Biotechnol. 26, 1117-1124.

Ryan, S. G., Buckwalter, M. S., Lynch, J. W., Handford, C. A., Segura, L., Shiang, R., Wasmuth,J.J., Camper, S.A., Schofield, P., and O'Connell, P. (1994). A missense mutation in the gene encoding the $\alpha 1$ subunit of the inhibitory glycine receptor in the spasmodic mouse. Nat. Genet. 7, 131-135.

Shiang, R., Ryan, S. G., Zhu, Y.Z., Fielder, T. J., Allen, R. J., Fryer, A., Yamashita, S., O'Connell, P., and Wasmuth, J. J.
(1995). Mutational analysis of familial and sporadic hyperekplexia. Ann. Neurol. 38, 85-91.

Shiang, R., Ryan, S. G., Zhu, Y. Z., Hahn, A. F., O'Connell, P., and Wasmuth, J. J. (1993). Mutations in the $\alpha 1$ subunit of the inhibitory glycine receptor cause the dominant neurologic disorder, hyperekplexia. Nat. Genet. 5, 351-358.

Tsai, G., Ralph-Williams, R. J., Martina, M., Bergeron, R., Berger-Sweeney, J., Dunham, K. S., Jiang, Z., Caine, S. B., and Coyle, J. T. (2004). Gene knockout of glycine transporter 1: characterization of the behavioral phenotype. Proc. Natl. Acad. Sci. U.S.A. 101, 8485-8490.

Vigevano, F., Di Capua, M., and Dalla Bernardina, B. (1989). Startle disease: an avoidable cause of sudden infant death. Lancet 1, 216.

Wheeler, D. A, Srinivasan, M., Egholm, M., Shen, Y., Chen, L., McGuire, A., He, W., Chen, Y. J., Makhijani, V., Roth, G. T., Gomes, X., Tartaro, K., Niazi, F., Turcotte, C. L., Irzyk, G. P., Lupski, J. R., Chinault, C., Song, X. Z., Liu, Y., Yuan, Y., Nazareth, L., Qin, X., Muzny, D. M., Margulies, M., Weinstock, G. M., Gibbs, R. A., and Rothberg, J.M. (2008). The complete genome of an individual by massively parallel DNA sequencing. Nature 454, 872-877.
Wheeler, D. L., Barrett, T., Benson, D. A. Bryant, S. H., Canese, K., Chetvernin, V., Church, D. M., Dicuccio, M., Edgar, R., Federhen, S., Feolo, M., Geer, L. Y., Helmberg, W., Kapustin, Y., Khovayko, O., Landsman, D. Lipman, D. J., Madden, T. L., Maglott, D. R., Miller, V., Ostell, J., Pruitt, K. D., Schuler, G. D., Shumway, M., Sequeira, E., Sherry, S. T., Sirotkin, K., Souvorov, A., Starchenko, G., Tatusov, R. L., Tatusova, T. A., Wagner, L., and Yaschenko, E. (2007). Database resources of the National Center for Biotechnology Information. Nucleic Acids Res. 36 (Database issue), 13-21.

White, H., and Potts, G. (2006). Mutation scanning by high resolution melt analysis. Evaluation of rotor-gene 6000 (Corbett Life Science), HR-1 and 384well lightscanner (Idaho Technology). National Genetics Reference Laboratory (Wessex). Available at: http://www.gene-quantification.de/ white-pott-hrm-comp-2006.pdf.

Yamashita, A., Singh, S. K., Kawate, T., Jin, Y., and Gouaux, E. (2005). Crystal structure of a bacterial homologue of $\mathrm{Na}^{+} / \mathrm{Cl}$--dependent neurotransmitter transporter. Nature 437, 215-223.

Zheng, J., Moorhead, M., Weng, L., Siddiqui, F., Carlton, V. E., Ireland, J. S., Lee, L., Peterson, J., Wilkins, J., Lin,
S., Kan, Z., Seshagiri, S., and Davis, R. W. and Faham, M. (2009). Highthroughput, high-accuracy arraybased resequencing. Proc. Natl. Acad. Sci. U.S.A. 106, 6712-6717.

Conflict of Interest Statement: The authors declare that the research was conducted in the absence of any commercial or financial relationships that could be construed as a potential conflict of interest.

Received: 02 October 2009; paper pending published:02 December 2009; accepted: 08 March 2010; published online: 23 March 2010.

Citation: Davies JS, Chung S-K, Thomas RH, Robinson A, Hammond CL, Mullins JGL, Carta E, Pearce BR, Harvey K, Harvey RJ and Rees MI (2010) The glycinergic system in human startle disease: a genetic screening approach. Front. Mol. Neurosci. 3:8. doi: 10.3389/fnmol.2010.00008 Copyright $@ 2010$ Davies, Chung, Thomas, Robinson, Hammond, Mullins, Carta, Pearce, Harvey, Harvey and Rees. This is an open-access article subject to an exclusive license agreement between the authors and the Frontiers Research Foundation, which permits unrestricted use, distribution, and reproduction in any medium, provided the original authors and source are credited. 